\title{
Obstetrical and Fetal Outcome in Teen Age Primigravida
}

\author{
F IQBAL S AZAD R TAYYAB \\ Department of Obstetrics \& Gynaecology. Fatima Jinnah Medical College/Sir Ganga Ram Hospital, Lahore. \\ Correspondence Dr. Farhat Iqbal, Assistant Professor
}

\begin{abstract}
A prospective case control study was carried out in Gynae Unit-II, Sir Ganga Ram Hospital, Lahore from December, 2002 to December, 2003. Total 60 cases were included in study. 30 were cases of primigravida $<19$ years of age (study group and 30 cases $>20$ years of age (control group) were studied after 24 weeks of gestation. The mean age for study group was $18.03 \pm 0.89$ and control group was $24.23 \pm 2.80$. 8 subjects (26\%) of PIH in study group and $3(10 \%)$ were in control group. 2 subjects $(6 \%)$ of UTI in study group and 0 case in control group. $6(20 \%)$ subjects were anemic in study group and only 1(3\%) was in control (6\%) no case in control group. Antepartum haemorrhage in 2 subjects $(83 \%)$ of normal vaginal delivery in study group there were 25 cases $(83 \%)$ while 22 subjects, $(73 \%)$ in control group. Instrumental delivery in $1(3 \%)$ subject in study group. 3 subjects $(10 \%)$ of postpartum haemorrhage were found in study group and only 1(3\%) in control group. Puerperal infection was present in 4 subjects $(13 \%)$ study group in 2 subjects $(6 \%)$ in control group. 10 neonates (33\%) were of low birth weight in study group, while 6 neonates $(60 \%)$ in study group not seen in control group. We concluded teenage pregnancy is high risk pregnancy.

Key words: Teenage primigravida, complication of antenatal intrapartum \& postpartum period.
\end{abstract}

Pregnancy is a physiological change and new experience in life of female. Maternal age and ethnicity are inter relating and interacting sociodermographic factors that influence maternal health and child bearing ${ }^{1}$. There is no consistent evidence to support the view that particular age is ideal for bearing the $1^{\text {st }}$ pregnancy: Although child bearing is least hazardous in women aged 20-29 years ${ }^{2}$.

Incidence of teenage pregnancy showed marked variations between developed and developing countries ${ }^{(3)}$. Each year more than 14 million adolescents become pregnant ${ }^{4}$. The births resulting from these pregnancies occurred for $20 \%$ of total births in USA ${ }^{\text {I }}$. Teenage pregnancy has been indentified as a target for health improvement by British Government. It has been identified in medical literature as problem of teenagers and society ${ }^{5}$. Teenage pregnancy c onstitute a high $\mathrm{r}$ isk group ${ }^{6}$. Genital infections such as chlamydia, tachomatis are common among sexually active teenage girls ${ }^{7}$. Lack of admission and compliance to antenatal care are associated with increased risk of pregnancy outcome $e^{8,9,10}$. In teenage pregnancy there is increased risk of anemia, $\mathrm{PIH}$ and perinatal mortality. The increased risk of PIH is significant, if pregnancy occurs within 24 months of menarche ${ }^{11}$.

Pregnant adolescents more likely experience abnormal labour patterns such as prolonged and precipitous labour and both may be associated with neonatal sequelae ${ }^{\prime \prime}$. Pregnant adolescence may be deficient in calcium Vit A \& iron. They need professional help in identifying food sources, to supplement or improve her nutrient intake, not only during pregnancy and but also in postpartum period. Therefore, the consequences of child bearing for adolescent parents, children and society are severe. A serious consequence is the acquisition of STD's particularly immune deficiency syndrome.
Information alone will not prevent teenage pregnancy but increased communication between parents and teenagers and teachers can improve outcome of teenage pregnancy. So special attension should be given to teenage pregnancies in antenatal intrapartum and postpartum period.

\section{Materials and methods:}

This study was conducted over a period of one year from Dec. 02 to Dec. 03 in Department of Obstetrics \& Gynaecology, Unit-II in Sir Ganga Ram Hospital, Lahore. It was cross sectional study. Total 60 patients were included in study. 30 cases were of $<19$ years primigravida and 30 controls of primigravidas $>20$ patients. Inclusion criteria were primigravida $<19$ years. After 24 weeks of gestation. Multiple pregnancy and before 24 weeks of gestation were excluded. Data analysis was performed on computer by using SPSS Version. 10. Frequency tables and percentages were calculated by same programme. Odds ratios (OR) was calculated and their statistical significance was tested. $\mathrm{P}$ value $<0.05$ was taken as significant.

\section{Results:}

Total 60 patients were included in study. 30 were of $<19$ years primigravida (study group) and 30 controls of primigravida $\geq$ than 20 years. In study group, 23 cases $(76.67 \%)$ were belonged to $18-19$ years of age and 7 cases $(23.33 \%)$ were between $16-17$ years of age. The mean age was $18.03 \pm 0.89$. Out of 30 controls 17 cases $(56.67 \%)$ were between $20-25$ years and 13 cases (43.33\%) were belonged to 26-30 years of age. The mean age was $24.23 \pm 2.80$. There were 8 cases $(26 \%)$ of $\mathrm{pIH}$ in study group and 3 patients $10 \%$ were in control group. 2 patients $(6 \%)$ of UTI in study group and no case in control group. Anaemia was present in 6 patients $(20 \%)$ of study group 
and 5 patients $(16 \%)$ in control group. There were 8 patients $(26 \%)$ of pre-term delivery in study group, while only $1(3 \%)$ was in control group. APH noted in 2 patients $(6 \%)$ in study group.

Table I shows complications in intrapartum period. There were 25 patients $(83 \%)$ of normal vaginal delivery in study group, while 22 patients $(73 \%)$ in control group. 5 patients ( $16 \%$ ) of had c aesarean s ection (LSCS) in s tudy group and 8 patients $(26 \%)$ in control group. Instrumental delivery occurred in only 1 patient $(3 \%)$ in study group. Statistically significant result of increased instrumental deliveries in teenage group.

Table I: Complications in intrapartum period

\begin{tabular}{|c|c|c|c|c|c|}
\hline \multirow[t]{2}{*}{ Complications } & \multicolumn{2}{|c|}{ Study group } & \multicolumn{2}{|c|}{ Control group } & \multirow{2}{*}{$\begin{array}{l}P \\
\text { value }\end{array}$} \\
\hline & No. & $\%$ & No. & $\%$ & \\
\hline $\begin{array}{l}\text { Normal vaginal } \\
\text { delivery }\end{array}$ & 25 & 83 & 22 & 73 & 0.347 \\
\hline L.S.C.S & 5 & 16 & 8 & 26 & 0.347 \\
\hline Instrumental & 1 & 3 & - & - & $<0.01 *$ \\
\hline
\end{tabular}

3 patients (10\%) of postpartum haemorrhage were found in study group, while only $1 \mathrm{p}$ atient (3\%) in c ontrol group. Postpartum infection was present in 4 patients (13\%) in study group in $2(6 \%)$ in control group. Statistically significant difference not found in both groups.

Table II: Fetal complications

\begin{tabular}{|c|c|c|c|c|c|}
\hline \multirow[t]{2}{*}{ Complication } & \multicolumn{2}{|c|}{ Study group } & \multicolumn{2}{|c|}{ Control group } & \multirow[t]{2}{*}{$P$ value } \\
\hline & No. & $\%$ & No. & $\%$ & \\
\hline $\begin{array}{l}\text { Low birth } \\
\text { weight }\end{array}$ & 10 & 33 & 6 & 20 & 0.242 \\
\hline Anomalies & 2 & 6 & - & - & $<0.01^{*}$ \\
\hline $\begin{array}{l}\text { ICU } \\
\text { admission }\end{array}$ & 8 & 26 & 1 & 3 & $<0.01 *$ \\
\hline
\end{tabular}

There were 10 babies (33\%) of low birth weight in study group, while 6 babies $(20 \%)$ in control group. Congenital anomalies were found in 2 babies $(6 \%)$ in study group, whereas no case in control group. 8 babies $(26 \%)$ were admitted in ICU in study group, only $1(3 \%)$ babies admitted to ICU in control group. Statistically significant number of babies with congenital anomalies found in teenage group and higher number of babies admitted in ICU in teen age group.

\section{Discussion:}

This study is done to see the effect of teenage on pregnancies and effect of pregnancy on teenagers.

In the present study risk of preterm (8\%) delivery more then control group, that leads to more admissions of neonates to ICU. Results of study are comparable with study conducted in Shaikh Zayed Hospital in March 2000. The risk of preterm delivery in that study was $13 \%$. There is general agreement that maternal youth is risk factor for preterm labour $^{12}$.
In study by Department of Obstetrics \& Gynaecology in University of Hong Kong showed high incidence of preterm delivery in teenagers ${ }^{13}$. In current study risk of $\mathrm{APH}$ is more and comparable to study conducted in south Africa oo $1^{14}$. Teenagers experienced high rate of placental abruption and was responsible for 2 IUD's. Perinatal mortality rate was twice as high as others. Poor outcome in teenagers in this study has been suggested due to noncompliance with antenatal checkup and lack of adherence to physician and midwifes.

Recently Bukulmez and Deren (2000) ${ }^{15}$ that age and lack of prenatal care were significant predictors of perinatal complications, after controlling for such risks, teenagers are not at great risk of on adverse obstetric out come than adult women of similar sociodemographic background.

In this study the risk of instrumental deliveries, preterm deliveries and low birth weight is high in teenage group Similarly in study conducted in Riyadh Armed Forces Hospital in Saudi Arabia in $1999^{16}$. Teen age pregnancy is associated with high rate of preterm delivery, pre eclampsia and low birth weight.

In over study, NICU admission rate was $26 \%$, similar results were seen in study conducted in Nigeria in 2003 that NICU admissions and low apgar score at 1 and $5 \mathrm{~min}$ in teenage pregnancy ${ }^{17}$. More vaginal deliveries in teenagers $83 \%$ in our study as compared to control group, which had more LSCS. $26 \%$, similar results are obtained in study in U.K ${ }^{18}$. In this study low birthrate was $33 \%$ in study group and $(20 \%)$ in control group similar results are seen in study conducted in Saudi Arabia ${ }^{19}$.

\section{Conclusion:}

This study indicates an increase risk of developing at least some complications of pregnancy and poor neonatal outcome, especially preterm delivery, pre-eclampsia, congenital malformations, intrauterine death and low birth weight infants. Preterm delivery rate was $(26 \%)$ and admission to neonatal ICU was also (26\%).

There is need for appropriate, education in pregnancy and advice and support for labour and child care. They need emotional support and awareness about antenatal care and advice about contraception. Media should create awareness in people and government should support these policies.

\section{References:}

1. Wildshchuf HIJ. Sociodemographic factors age, parity social class. In: James DK, Steer PJ, Weiner CP, Gonik B, editors High Risk Pregnancy, $2^{\text {nd }}$ ed, London, W.B. Saunders: 1999, P 39-41

2. Golding J. editor. Maternal age and parity, social and biological effects on perinatal mortality. Report on International comparative study 1990

3. Sandler DP, Wilcox AJ, Horney LF, Age of menarche and subsequent reproductive events. Am J Epidemiol 1984 P1 19: 765-74. 
4. Desilva MO. Teenage sexual behaviour and pregnancy. Trend and determinent. In Studd J. editor, Progress in Obstetrics and Gynaecology, Vol 15 London Churchill Living Stone 2003, P 123-34

5. Jewell D, Tachi J. Teenage pregnancy, whose problem it is? Fam Pract 2000;1 7:522-8

6. Campbells Less C. Teen teachers $17^{\text {th }}$ ed. London, Arnold: 2000;96

7. Rahm VA, Gnarpe H, Odind V. Chlamydia trachomatus, among sexually active teenage girls $\mathrm{Br} \mathrm{J}$ Obstet Gynecol 1988:95

8. Fraser AM, Brockert JE, Ward RH, Association of young maternal age with adverse reproductive out come, $\mathrm{N}$ Engl J Med 1995;332:1113-7

9. Berkowitz G, Papiernik K, Epidemiology of preterm birth, Epidem, Rev 1993; 15:414-43

10. Scholl TO, Miller LK, Wexberg. Salmon R, Corr-Cofsky M, Shearer J. Prenatal care adequacy and outcome of adoloscent pregnancy. Effects on weight gain, preterm delivery and birth weight. Obstet Gynecol 1987;69:312-6
11. Carrol CS, Pregnancy in adoloscent. In: Rivilln EM, Martin WR e ditors, Manual of c linical problems in obstetrics and gynaecology. $5^{\text {th }}$ ed, New York Lippincoff, Williams \& Wilkins 2000:85-7

12. East PL. Kiernan EA, Risks among youths who have multiple sisters, who were adoloscent parents. Fam Plann Perspect 2001;33:75-80

13. Lao TT, HO, LF. Obstetric outcome of teenage pregnancies. Hum Reprod 1998;13:3228-32

14. Hall RD, Swat R, Grove D, Odendaal JH. The influence of maternal a ge on pregnancy o utcome in patients $w$ ith e arly onset, severe preeclampsia. J Obstet Gynecol 2001;3:246-9

15. Bukulmez O, Deren O. Perinatal outcome in adooloscent pregnancies, a case control study from Turkish University Hospital Eue J Obstet Gynecol 2000;158:892-8

16. Mesleh RA, AnAqi AS, Kurdi AM, teenage pregnancy Sind Med J 2001;22:864-7

17. Airede RL, Ekele AB, Adoloscent maternal mortality in Sooto, Nigeria, J Obstet Gynaecol 2003;23:163-5

18. Appleby L. Suicide during pregnancy and in $1^{\text {st }}$ postnatal year. Br Med J 1991;302:137-40 